\title{
Congenital Diaphragmatic Hernia: 10-Year Evaluation of Survival, Extracorporeal Membrane Oxygenation, and Foetoscopic Endotracheal Occlusion in Four High-Volume Centres
}

\author{
Kitty G. Snoek ${ }^{\mathrm{a}}$ Anne Greenough ${ }^{c}$ Joost van Rosmalen ${ }^{\mathrm{b}} \quad$ Irma Capolupo ${ }^{\mathrm{d}}$ \\ Thomas Schaible ${ }^{\mathrm{e}}$ Kamal Alic René M. Wijnen ${ }^{\mathrm{a}}$ Dick Tibboel $^{\mathrm{a}}$ \\ a Intensive Care and Department of Paediatric Surgery, Erasmus Medical Centre-Sophia Children's Hospital, and \\ ${ }^{b}$ Department of Biostatistics, Erasmus Medical Centre, Rotterdam, The Netherlands; ' Division of Asthma, Allergy \\ and Lung Biology, MRC \& Asthma UK Centre in Allergic Mechanisms of Asthma, King's College London, London, UK; \\ ${ }^{\mathrm{d}}$ Department of Medical and Surgical Neonatology, Bambino Gesu Children's Hospital, Rome, Italy; ${ }^{\mathrm{e}}$ Department of \\ Pediatrics, Universitätsmedizin Mannheim, Mannheim, Germany
}

\section{Keywords}

Congenital diaphragmatic hernia - Extracorporeal membrane oxygenation · Foetal intervention - Mortality

\begin{abstract}
Background: Congenital diaphragmatic hernia $(\mathrm{CDH})$ is a severe congenital anomaly with significant mortality. Objectives: The aim of this study was to determine if there were trends in survival over the last decade and to compare patient populations, treatment options, and survival rates between 4 high-volume centres, and hence determine which factors were associated with survival. Methods: In 4 highvolume $\mathrm{CDH}$ centres from the $\mathrm{CDH}$ EURO Consortium, data from all CDH patients born between 2004 and 2013 were analysed. The predictive value of variables known at birth and the influence of centre-specific treatments (extracorporeal membrane oxygenation, ECMO, and foetoscopic endotracheal occlusion, FETO) on survival were evaluated in multivariable logistic regression analyses. Results: Nine hundred and seventy-five patients were included in the analysis, of
\end{abstract}

\section{KARGER}

(C) 2017 S. Karger AG, Basel

E-Mail karger@karger.com

www.karger.com/neo whom 274 (28.1\%) died. ECMO was performed in 259 patients, of whom 81 (31.3\%) died. One hundred and forty-five patients (14.9\%) underwent FETO, and from those 76 patients $(52.4 \%)$ survived. Survival differed significantly between years $(p=0.006)$ and between the 4 centres $(p<$ $0.001)$. In the multivariable logistic regression analysis, lungto-head ratio, gestational age at birth, ECMO, centre of birth, and year of birth were significantly associated with survival, whereas FETO was not. Conclusions: The patient populations were different between centres, which influenced outcomes. There was a significant variability in survival over time and between centres, which should be taken into consideration in the planning of future trials.

(c) 2017 S. Karger AG, Basel

\section{Introduction}

Congenital diaphragmatic hernia $(\mathrm{CDH})$ is a severe congenital anomaly with a high outcome variability [1]. Over the last decade, new strategies have been introduced

Dick Tibboel, MD, PhD

Intensive Care and Department of Paediatric Surgery Erasmus Medical Centre-Sophia Children's Hospital, Room Sp-2430 PO Box 2040, NL-3000 CA Rotterdam (The Netherlands)

E-Mail d.tibboel@erasmusmc.nl 
to evaluate and manage $\mathrm{CDH}$ patients. It is likely that survival may have improved over that time, and an aim of our study was to test this hypothesis.

Patient characteristics, such as foetal liver position (intra-abdominal or intrathoracic) [2], stomach position [3], lung-to-head ratio (LHR) [4], observed-to-expected LHR [5], and the diaphragmatic defect size [6] can influence outcome as well as treatment in a high- or low-volume centre. There are differences in opinion about whether extracorporeal membrane oxygenation (ECMO) improves survival as no specific trials have been conducted with the primary aim of evaluating the role of ECMO specifically for high-risk $\mathrm{CDH}$ patients $[7,8]$. The UK ECMO randomised trial investigated the role of ECMO for neonates, but only $19 \%$ of those included had $\mathrm{CDH}$ and there was no significant difference in that subgroup with regard to survival [9]. In a multicentre, randomised clinical trial (RCT) of the initial ventilation strategy, in which centres with and without ECMO availability were included, no difference in survival between centres was observed [10]. Many CDH centres chose not to use ECMO because of the perceived poor outcome of $\mathrm{CDH}$ infants requiring ECMO [11]. Therefore, an important question is whether or not ECMO influences survival? In the most severe, prenatally detected $\mathrm{CDH}$ cases, foetoscopic endotracheal occlusion (FETO) may improve outcome $[12,13]$. To date, however, the results of only 1 small RCT have been reported. In an RCT of 20 severe CDH patients of FETO versus postnatal management, survival was significantly better in the FETO group [14]. Thus, it is important to further determine the influence of FETO on survival, with the results of the socalled TOTAL trial due to become available in 2018. By analysing the results of 4 high-volume $\mathrm{CDH}$ centres, our further aim, therefore, was to compare patient populations, treatment options, and survival rates to determine which factors were associated with survival.

\section{Patients and Methods}

An observational cohort study was performed involving all patients with $\mathrm{CDH}$ who were born between January 2004 and December 2013 and treated in 4 high-volume centres of the $\mathrm{CDH}$ EURO Consortium. The 4 centres were in Rotterdam, London, Mannheim, and Rome. From 2008, all patients were treated according to a standardised treatment protocol [15]. The standardised treatment included immediate intubation after birth, permissive hypercapnia, initial ventilation by high-frequency oscillation or conventional mechanical ventilation, surgical repair of the defect after physiological stabilisation, no routine chest tube placement, and no routine use of paralysis. ECMO was only used routinely in some centres. In Rotterdam and Mannheim, ECMO

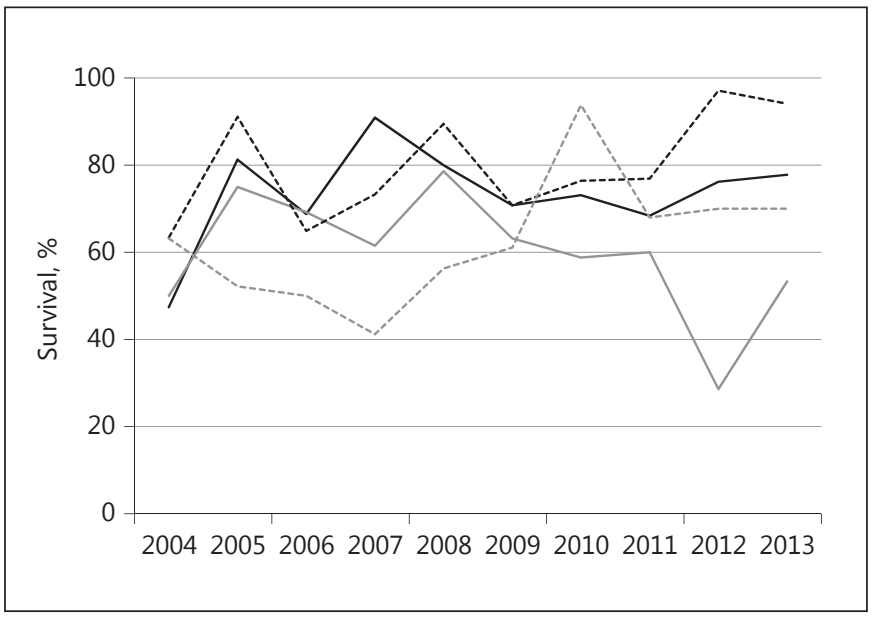

Fig. 1. Survival of $\mathrm{CDH}$ by centre over the years. The solid black line represents Rotterdam, solid grey line represents London, dashed black line represents Mannheim, and dashed grey line represents Rome.

therapy was available during the whole inclusion period, in Rome, ECMO was available in 2013 only, and in London infants could be transferred to an ECMO centre. FETO was available in the 4 centres on a compassionate basis.

The ECMO criteria were: an inability to maintain preductal saturations $>85 \%$ or postductal saturations $>70 \%$; a high $\mathrm{PaCO}_{2}$ with a respiratory acidosis $(\mathrm{pH}<7.15)$ despite the optimisation of ventilatory management (peak inspiratory pressure $>28 \mathrm{~cm} \mathrm{H}_{2} \mathrm{O}$ or mean airway pressure $>17 \mathrm{~cm} \mathrm{H}_{2} \mathrm{O}$ to achieve saturation $>85 \%$, inadequate oxygen delivery with a metabolic acidosis, lactate level $>5 \mathrm{mmol} / \mathrm{L}$, and $\mathrm{pH}<7.15$ ); systemic hypotension, resistant to fluid and inotropic therapy, resulting in urine output $<0.5 \mathrm{~mL} / \mathrm{kg} / \mathrm{h}$ for at least $12-24 \mathrm{~h}$, and oxygenation index (mean airway pressure $\left.\times \mathrm{FiO}_{2} \times 100 / \mathrm{PaO}_{2}\right) \geq 40$. In Mannheim before 2008, the ECMO criteria included an oxygenation index $>35$ for $0.5-6 \mathrm{~h}$ and a $\mathrm{pH}$ $<7.25$. In London, FETO therapy was only offered within the context of research trials (NCT01240057) from 2013 onwards, and before 2010 as compassionate use. The inclusion criteria for FETO were: isolated left-sided $\mathrm{CDH}$ and severe pulmonary hypoplasia, defined as observed-to-expected LHR $<25 \%$ as measured prior to 29 weeks +6 days, irrespective of the liver position. As the subjects were not being submitted to any handling and rules of human behaviour were not being imposed, institutional review board approval was waived.

Patient demographics and management strategies, including prenatal diagnosis, LHR, FETO, gestational age, birth weight, gender, side of the defect, liver position (intrathoracic or intra-abdominal determined during surgical repair), type of repair (primary closure or patch repair), age at surgical repair, ECMO, ventilation days in survivors, inhaled nitric oxide, and survival were collected from the medical records. Death during the first year after birth was determined.

Analysis

To determine whether differences in the demographics of the infants in the 4 centres were statistically significant, $\chi^{2}$ tests for cat-
Snoek et al. 
Table 1. Background characteristics by centre

\begin{tabular}{|c|c|c|c|c|c|}
\hline & $\begin{array}{l}\text { Rotterdam } \\
(n=195)\end{array}$ & $\begin{array}{l}\text { London } \\
(n=127)\end{array}$ & $\begin{array}{l}\text { Mannheim } \\
(n=469)\end{array}$ & $\begin{array}{l}\text { Rome } \\
(n=184)\end{array}$ & $p$ value \\
\hline Prenatal diagnosis & $139(71.3)$ & $125(98.4)$ & $407(86.8)$ & $149(81.0)$ & $<0.001$ \\
\hline LHR & $1.47(1.00-1.99)$ & $1.65(1.33-2.20)$ & $1.60(1.25-1.99)$ & $1.82(1.44-2.55)$ & $<0.001$ \\
\hline FETO & $9(4.6)$ & $84(66.1)$ & $48(10.2)$ & $4(2.2)$ & $<0.001$ \\
\hline Missing & $0(0)$ & $0(0)$ & $108(23.0)$ & $0(0)$ & \\
\hline Gestational age, weeks & $38.3(37.1-39.1)$ & $35.7(33.7-38.6)$ & $37.6(36.1-38.4)$ & $38.0(37.0-39.0)$ & $<0.001$ \\
\hline Premature born & $41(21.0 \%)$ & $76(59.8)$ & $153(32.6)$ & $28(15.2)$ & $<0.001$ \\
\hline Birth weight, $g$ & $3,000(2,598-3,239)$ & $3,200(2,345-3,600)$ & $2,870(2,480-3,210)$ & $2,930(2,600-3,230)$ & 0.004 \\
\hline Male gender & $113(57.9)$ & $58(45.7)$ & $274(58.4)$ & $112(60.9)$ & 0.04 \\
\hline Side of the defect & & & & & 0.11 \\
\hline Left & $164(84.1)$ & $115(90.6)$ & $381(81.2)$ & $151(82.1)$ & \\
\hline Right & $31(15.9)$ & $12(9.4)$ & $83(17.7)$ & $30(16.3)$ & \\
\hline Bilateral & $0(0)$ & $0(0)$ & $3(0.6)$ & $3(1.6)$ & \\
\hline Missing & $0(0)$ & $0(0)$ & $2(0.4)$ & $0(0)$ & \\
\hline Liver position: intrathoracic & $70(40.2)$ & $48(54.5)$ & $237(58.5)$ & $48(36.9)$ & $<0.001$ \\
\hline Type of repair & & & & & $<0.001$ \\
\hline Primary closure & $42(21.5)$ & $38(43.2)$ & $88(18.8)$ & $89(48.4)$ & \\
\hline Patch repair & $132(67.7)$ & $50(56.8)$ & $306(65.2)$ & $41(22.3)$ & \\
\hline No repair & $21(10.8)$ & $39(30.7)$ & $64(13.6)$ & $54(29.3)$ & \\
\hline Missing & $0(0)$ & $0(0)$ & $11(2.3)$ & $0(0)$ & \\
\hline Age at surgical repair, days & $4.0(3.0-6.0)$ & $5.0(3.0-7.0)$ & $6.0(3.0-12.0)$ & $3.0(2.0-4.0)$ & $<0.001$ \\
\hline ECMO & $62(31.8)$ & $0(0)$ & $196(41.8)$ & $1(0.5)$ & 0.01 \\
\hline Ventilation in survivors, days & $9.8(6.0-20.1)$ & $13.0(9.0-18.0)$ & $21.3(11.0-30.1)$ & $9.0(6.0-15.0)$ & $<0.001$ \\
\hline iNO & $105(53.8)$ & $68(53.5)$ & $266(56.7)$ & $79(43.2)$ & $<0.001$ \\
\hline Survival & $142(72.8)$ & $75(59.1)$ & $370(78.9)$ & $114(62.0)$ & $<0.001$ \\
\hline
\end{tabular}

Data are presented as $n(\%)$ or median (IQR). Liver position was determined at surgical repair. LHR, lung-to-head ratio; FETO, foetoscopic tracheal occlusion; ECMO, extracorporeal membrane oxygenation; iNO, inhaled nitric oxide.

egorical data or Kruskal-Wallis tests for continuous data were used. Mann-Whitney $U$ tests for continuous data and $\chi^{2}$ tests for categorical data were applied to compare the centre of birth and patient characteristics that were known at birth between survivors and non-survivors. In these univariate comparisons, the year of birth was treated as a categorical variable. Associations between prenatal diagnosis, LHR, FETO, gestational age, gender, side of the defect, ECMO, centre, and year of birth as independent variables and survival were determined using multivariable logistic regression analysis. The goodness-of-fit of the logistic regression model was assessed using the Hosmer-Lemeshow test. Analyses were performed using SPSS 22.0 for Windows (SPSS Inc., Chicago, IL, USA).

\section{Results}

During the study period, there were a total of $975 \mathrm{CDH}$ patients, of whom 274 (28.1\%) died. A prenatal diagnosis was made in $820(84.1 \%)$ patients. Overall, there was a significant difference in survival over time $(p=0.006$;

Congenital Diaphragmatic Hernia:

Survival, ECMO, and FETO
Fig. 1). The survival rate differed from 29 to $97 \%$ over the years and between the centres.

Prenatal diagnosis, LHR, FETO, gestational age, birth weight, gender, liver position at surgical repair, type of repair, age at surgical repair, ECMO, ventilation days in survivors, use of inhaled nitric oxide, and survival were significantly different between the 4 centres (Table 1). Survivors significantly less often had a prenatal diagnosis, had higher LHRs and gestational ages, and a greater proportion had a left-sided defect than non-survivors (Table 2).

There were also significant differences in survival regarding the year of birth and centre of birth (Table 2). In Mannheim, 196 patients (41.8\%) received ECMO and $153(78.1 \%)$ of the ECMO-treated patients survived. In Rotterdam, 62 patients (31.8\%) received ECMO and 25 (40.3\%) of these survived. ECMO-treated patients in Rotterdam had lower LHRs and more often had a patch repair compared to the ECMO-treated patients in

Neonatology 2018;113:63-68 65 
Table 2. Background characteristics for survivors and non-survivors

\begin{tabular}{|c|c|c|c|}
\hline & $\begin{array}{l}\text { Survivors } \\
(n=701)\end{array}$ & $\begin{array}{l}\text { Non-survivors } \\
(n=274)\end{array}$ & $p$ value \\
\hline Prenatal diagnosis & $570(81.4)$ & $250(85.0)$ & $<0.001$ \\
\hline LHR & $1.73(1.40-2.20)$ & $1.35(1.00-1.73)$ & $<0.001$ \\
\hline FETO & $76(12.5)$ & $69(25.2)$ & $<0.001$ \\
\hline Missing & $92(13.1)$ & $16(5.8)$ & \\
\hline $\begin{array}{l}\text { Gestational age, } \\
\text { weeks }\end{array}$ & $38.0(37.0-38.9)$ & $37.0(35.0-38.0)$ & $<0.001$ \\
\hline Gender & & & 0.50 \\
\hline Male & $405(57.8)$ & $152(55.5)$ & \\
\hline Female & $295(42.1)$ & $122(44.5)$ & \\
\hline Side of the defect & & & 0.02 \\
\hline Left & $595(84.9)$ & $216(78.8)$ & \\
\hline Right & $103(14.7)$ & $53(19.3)$ & \\
\hline Bilateral & $2(0.3)$ & $4(1.5)$ & \\
\hline Missing & $1(0.1)$ & $1(0.4)$ & \\
\hline ECMO & $178(25.4)$ & $81(29.6)$ & 0.20 \\
\hline Centre & & & $<0.001$ \\
\hline Rotterdam & $142(20.3)$ & $53(19.3)$ & \\
\hline London & $75(10.7)$ & $52(19.0)$ & \\
\hline Mannheim & $370(52.9)$ & $99(36.1)$ & \\
\hline Rome & $114(16.3)$ & $70(25.5)$ & \\
\hline Year of birth & & & 0.01 \\
\hline 2004 & $51(58.6)$ & $36(41.4)$ & \\
\hline 2005 & $69(78.4)$ & $19(21.6)$ & \\
\hline 2006 & $67(63.2)$ & $39(36.8)$ & \\
\hline 2007 & $58(67.4)$ & $28(32.6)$ & \\
\hline 2008 & $91(81.2)$ & $21(18.8)$ & \\
\hline 2009 & $74(67.9)$ & $35(32.1)$ & \\
\hline 2010 & $86(75.4)$ & $28(24.6)$ & \\
\hline 2011 & $76(71.7)$ & $30(28.3)$ & \\
\hline 2012 & $68(75.6)$ & $22(24.4)$ & \\
\hline 2013 & $61(79.2)$ & $16(20.8)$ & \\
\hline
\end{tabular}

Data are presented as $n(\%)$ or mean \pm SD. Numbers do not always add up to the total number of the group because of missing data. LHR, lung-to-head ratio; FETO, foetoscopic tracheal occlusion; ECMO, extracorporeal membrane oxygenation.

Mannheim. In Rome in 2013, 1 patient received ECMO and died. None of the patients from London received ECMO. ECMO use between the survivors and non-survivors was not statistically significant. FETO was significantly more often used in non-survivors (25.2\%) than in patients who survived (12.5\%).

In the multivariable logistic regression analysis, a lower LHR, lower gestational age, ECMO, centre of birth, and year of birth were significantly associated with death (Table 3). FETO was not significantly associated with death. The $p$ value of the Hosmer-Lemeshow test was larger than 0.05 , indicating an adequate model calibration.
Table 3. Multivariable logistic regression analysis for survival of $\mathrm{CDH}$ patients

\begin{tabular}{lccc}
\hline Variable & OR & $95 \%$ CI & $p$ value \\
\hline LHR & 4.30 & $2.98-6.21$ & $<0.001$ \\
FETO & 0.67 & $0.36-1.26$ & 0.21 \\
Gestational age, weeks & 1.22 & $1.10-1.35$ & $<0.001$ \\
Male gender & 0.87 & $0.59-1.29$ & 0.87 \\
Side of the defect & & & 0.39 \\
$\quad$ Left & Ref. & & \\
$\quad$ Bilateral & 0.32 & $0.04-2.68$ & 0.29 \\
$\quad$ Right & 1.27 & $0.73-2.20$ & 0.40 \\
ECMO & 0.49 & $0.30-0.81$ & 0.005 \\
Centre & & & $<0.001$ \\
$\quad$ London & Ref. & & \\
$\quad$ Rotterdam & 1.70 & $0.73-3.95$ & 0.22 \\
$\quad$ Rome & 0.35 & $0.15-0.79$ & 0.01 \\
$\quad$ Mannheim & 3.39 & $1.61-7.14$ & 0.001 \\
Year of birth & 1.09 & $1.01-1.17$ & 0.03 \\
\hline
\end{tabular}

LHR, lung-to-head ratio; FETO; foetoscopic tracheal occlusion; ECMO, extracorporeal membrane oxygenation; OR, odds ratio; 95\% CI, 95\% confidence interval; Ref., reference category.

\section{Discussion}

We have demonstrated variability in survival across a 10 -year period and between 4 high-volume $\mathrm{CDH}$ centres. In addition, we have highlighted that the patient populations differed significantly between the centres and this influenced outcome. The survival rate was very different each year (Fig. 1).

In the univariate analysis, we did not find a significant difference in ECMO use between the survivors and non-survivors. In the multivariable analysis with correction for patient characteristics, however, we found that ECMO was significantly associated with death. This may be explained by the fact that only the most severe $\mathrm{CDH}$ cases received ECMO. The frequency of use of ECMO and the outcomes was different between centres. In Mannheim, $42 \%$ of the patients received ECMO and $78 \%$ of them survived, whereas in Rotterdam $32 \%$ of the patients received ECMO and only $41 \%$ of them survived. ECMO-treated patients in Rotterdam, however, had lower LHRs and more often had a patch repair, suggesting they were in a more severe category. To identify for which subgroup of $\mathrm{CDH}$ patients ECMO might be most beneficial, predictive postnatal clinical models, such as the Score for Neonatal Acute Physiology II [16] or the clinical prediction score published by Brindle et al. [17], may be useful. Neonatology 2018;113:63-68
DOI: $10.1159 / 000480451$
Snoek et al. 
FETO was significantly more often used in non-survivors, likely reflecting the selection criteria for compassionate use. Because FETO was only used on a compassionate basis, it precludes any meaningful conclusion with regards to its influence on survival. The TOTAL trial [18] will hopefully give a definitive answer regarding the benefit of FETO for patients with severe $\mathrm{CDH}$.

High-volume $\mathrm{CDH}$ centres have more experience in treating $\mathrm{CDH}$ infants than low-volume centres and better outcomes [19]. Nevertheless, the patient characteristics were very different between the 4 high-volume centres and, despite correction for patient characteristics in the multivariable analysis, the centre significantly influenced survival. This emphasises the need for correction for centre in analyses of future multicentre studies on $\mathrm{CDH}$. Moreover, long-term follow-up programs on these patients are essential to assess the quality of life.

Our study has many strengths and some limitations. We examined the outcome of a large sample $(n=975)$ over 10 years in 4 high-volume centres. Despite all centres agreeing on the use of a consistent protocol during the study period, we cannot rule out the possibility that differences in physicians, nursing staff, and training may have influenced our results. This needs to be taken into account in future RCTs.

\section{Conclusion}

We demonstrated variability in the survival of $\mathrm{CDH}$ patients over time and between centres. Such differences need to be taken into account when planning future trials.

\section{Disclosure Statement}

The authors have no financial relationships or other conflicts of interest relevant to this article to disclose.

\section{Funding Sources}

No funding was received in support of this work.

\section{Author Contributions}

K.G.S. conceptualised and designed the study, carried out the initial analyses, and drafted the initial manuscript. A.G., I.C., T.S., K.A., and R.M.W. coordinated and supervised data collection and critically reviewed the manuscript. J.V.R. carried out the initial analyses and reviewed and revised the manuscript. D.T. conceptualised and designed the study and critically reviewed the manuscript. All authors approved the final manuscript for submission.

\section{References}

1 Grover TR, Murthy K, Brozanski B, Gien J, Rintoul N, Keene S, Najaf T, Chicoine L, Porta N, Zaniletti I, Pallotto EK; Children's Hospitals Neonatal Consortium: Short-term outcomes and medical and surgical interventions in infants with congenital diaphragmatic hernia. Am J Perinatol 2015;32:1038-1044.

2 Hidaka N, Ishii K, Mabuchi A, Yamashita A, Ota S, Sasahara J, Murata M, Mitsuda N: Associated anomalies in congenital diaphragmatic hernia: perinatal characteristics and impact on postnatal survival. J Perinat Med 2015;43:245-252.

3 Basta AM, Lusk LA, Keller RL, Filly RA: Fetal stomach position predicts neonatal outcomes in isolated left-sided congenital diaphragmatic hernia. Fetal Diagn Ther 2016;39:248-255.

4 Lusk LA, Wai KC, Moon-Grady AJ, Basta AM, Filly R, Keller RL: Fetal ultrasound markers of severity predict resolution of pulmonary hypertension in congenital diaphragmatic hernia. Am J Obstet Gynecol 2015; 213:e211-e218.
5 Jani JC, Benachi A, Nicolaides KH, Allegaert K, Gratacos E, Mazkereth R, Matis J, Tibboel D, van Heijst A, Storme L, Rousseau V, Greenough A, Deprest JA; Antenatal-CDH-Registry Group: Prenatal prediction of neonatal morbidity in survivors with congenital diaphragmatic hernia: a multicenter study. Ultrasound Obstet Gynecol 2009;33:64-69.

6 Congenital Diaphragmatic Hernia Study Group; Morini F, Valfre L, Capolupo I, Lally KP, Lally PA, Bagolan P: Congenital diaphragmatic hernia: defect size correlates with developmental defect. J Pediatr Surg 2013;48: 1177-1182.

7 Davis JS, Ryan ML, Perez EA, Neville HL, Bronson SN, Sola JE: ECMO hospital volume and survival in congenital diaphragmatic hernia repair. J Surg Res 2012;178:791-796.

8 Kotecha S, Barbato A, Bush A, Claus F, Davenport M, Delacourt C, Deprest J, Eber E, Frenckner B, Greenough A, Nicholson AG, Antón-Pacheco JL, Midulla F: Congenital diaphragmatic hernia. Eur Respir J 2012;39: 820-829.
9 UK Collaborative ECMO Trial Group: UK collaborative randomised trial of neonatal extracorporeal membrane oxygenation. Lancet 1996;348:75-82.

10 Snoek KG, Capolupo I, van Rosmalen J, de Jongste-van den Hout L, Vijfhuize S, Greenough A, Wijnen RM, Tibboel D, Reiss IKM; CDH EURO Consortium: Conventional mechanical ventilation versus high-frequency oscillatory ventilation for congenital diaphragmatic hernia: a randomized clinical trial. Ann Surg 2016;263:867-874.

11 ELSO Registry: ECLS Registry Report International Summary. Ann Arbor, ELSO Registry, 2014.

12 Deprest J, Jani J, Gratacos E, Vandecruys H, Naulaers G, Delgado J, Greenough A, Nicolaides K; FETO Task Group: Fetal intervention for congenital diaphragmatic hernia: the European experience. Semin Perinatol 2005; 29:94-103.
Congenital Diaphragmatic Hernia:

Survival, ECMO, and FETO
Neonatology 2018;113:63-68 DOI: $10.1159 / 000480451$ 
13 Cundy TP, Gardener GJ, Andersen CC, Kirby CP, McBride CA, Teague WJ: Fetoscopic endoluminal tracheal occlusion (FETO) for congenital diaphragmatic hernia in Australia and New Zealand: are we willing, able, both or neither? J Paediatr Child Health 2014;50:226233.

14 Ruano R, Yoshisaki CT, da Silva MM, Ceccon ME, Grasi MS, Tannuri U, Zugaib M: A randomized controlled trial of fetal endoscopic tracheal occlusion versus postnatal management of severe isolated congenital diaphragmatic hernia. Ultrasound Obstet Gynecol 2012;39:20-27.
15 Reiss I, Schaible T, van den Hout L, Capolupo I, Allegaert K, van Heijst A, Gorett Silva M, Greenough A, Tibboel D; CDH EURO Consortium: Standardized postnatal management of infants with congenital diaphragmatic hernia in Europe: the CDH EURO Consortium consensus. Neonatology 2010; 98:354-364.

16 Coleman AJ, Brozanski B, Mahmood B, Wearden PD, Potoka D, Kuch BA: First 24-h SNAP-II score and highest $\mathrm{PaCO}_{2}$ predict the need for ECMO in congenital diaphragmatic hernia. J Pediatr Surg 2013;48:2214-2218.
17 Brindle ME, Cook EF, Tibboel D, Lally PA, Lally KP; Congenital Diaphragmatic Hernia Study Group: A clinical prediction rule for the severity of congenital diaphragmatic hernias in newborns. Pediatrics 2014;134:e413-e419.

18 Deprest J, Brady P, Nicolaides K, Benachi A, Berg C, Vermeesch J, Gardener G, Gratacos E: Prenatal management of the fetus with isolated congenital diaphragmatic hernia in the era of the TOTAL trial. Semin Fetal Neonatal Med 2014;19:338-348.

19 Bucher BT, Guth RM, Saito JM, Najaf T, Warner BW: Impact of hospital volume on in-hospital mortality of infants undergoing repair of congenital diaphragmatic hernia. Ann Surg 2010;252:635-642. 